\title{
Pomphorhynchidae and Quadrigyridae (Acanthocephala), including a new genus and species (Pallisentinae), from freshwater fishes, Cobitidae and Cyprinodontidae, in Turkey
}

\author{
Lesley R. Smales ${ }^{1}$, Ali Aydogdu² and Yilmaz Emre ${ }^{3}$ \\ ${ }^{1}$ South Australian Museum, North Terrace, Adelaide, South Australia 5000, Australia; \\ ${ }^{2}$ Mustafakemalpasa Vocational School, Uludag University, Mustafakemalpasa, Bursa, Turkey; \\ ${ }^{3}$ Mediterranean Fisheries Research, Production and Training Institute, Antalya, Turkey
}

\begin{abstract}
During a survey of freshwater fishes from Turkey two species of Acanthocephala, one of them new, were found. Pomphorhynchus tereticollis (Pomphorhynchidae) is reported at $24 \%$ prevalence in 37 Cobitis bilseli (Cobitidae) from Lake Beysehir, Konya, for the first time. The eoacanthoacaphalan Triaspiron aphanii gen. n. et sp. n. (Quadrigyridae), at a prevalence of $90 \%$, is described from 29 Aphanius mento (Cyprinodontidae), from Kirkgöz Springs, Antalya. The new genus most closely resembles Raosentis Datta, 1947, both having a small spindle shaped trunk, and Acanthogyrus Thapar, 1927, both having a proboscis armature of three circles of hooks. Triaspiron differs from Raosentis in proboscis shape, cylindrical not globular, proboscis armature, three circles, a total of 16 hooks in all, not four circles, a total of 26-30 hooks in all, and trunk spination, two fields of spines in the anterior field with spines arranged in up to 40 circular rows, not a single field with 9-17 rows of spines. Triaspiron differs from Acanthogyrus in having fewer proboscis hooks, 16 compared with 18-24, arranged in three circles, one anterior and two posteriorly placed, with an unarmed region between, not three circles of hooks evenly spaced, and two fields of trunk spines, not one.
\end{abstract}

Keywords: Acanthocephala, taxonomy, morphology, Triaspiron aphanii, Pomphorhynchus tereticollis, freshwater fish, Cobitis bilseli, Aphanius mento, Lake Beysehir, Kirkgöz Springs

The family Quadrigyridae Van Cleave, 1920 (Eoacanthocephala: Gyracanthocephala) with two subfamilies, the Quadrigyrinae Van Cleave, 1920, comprising three genera, and the Pallisentinae Van Cleave, 1928 comprising seven genera, Acanthocephalorhynchoides Kostylew, 1941; Acanthogyrus Thapar, 1927; Hexaspiron Dollfus et Golvan, 1956; Pararaosentis Amin, Heckmann, Van Ha, Van Luc et Ngoc Doanh, 2000; Palliolisentis Machado, 1960; Pallisentis Van Cleave, 1928; and Raosentis Datta, 1947, is found in freshwater fishes from Asia, Africa, Central and South America (Golvan 1959; Amin et al. 2000). The pattern of trunk spination, i.e. complete circles of spines in one or two regions separated by an unarmed zone, with spines in the second region extending over the trunk in circles or longitudinal rows, or circles of spines only in the anterior region that may be incomplete dorsally separate the Pallisentinae and the Quadrigyrinae (Amin 1987).

As part of a survey of the helminth parasites of fresh water fish in Antalya and Konya, Turkey, several host species including Cobitis bilseli (Cobitidae) and Aphanius mento (Heckel) (Cyprinodontidae) were sampled. Cobitis bilseli Battalgil is endemic to Lake Beysehir, Turkey
(Erkakhan et al. 1999). Aphanius mento by contrast is a regional species found in fresh to brackish waters across the Anatolian Peninsula, Turkey and from the Arabian Peninsula, Israel, Lebanon, western Jordania and Syria (Güclü and Kücük 2008). To the best of our knowledge the only records of helminths from either of these two host species are of larvae of the nematodes Raphidascaris sp. and Eustrongylides excises Jägerskiöld, 1909 from A. mento (see Güclü and Kücük 2008, Aydogdu et al. 2011a). During this study acanthocephalans were found, including Pomphorhynchus tereticollis (Rudolphi, 1809) and a new species of the Pallisentinae, which has necessitated the erection of a new genus described below.

\section{MATERIALS AND METHODS}

In 2009 a total of 37 specimens of Cobitis bilseli were collected from Lake Beysehir, Konya $\left(37^{\circ} 47^{\prime} \mathrm{N}, 31^{\circ} 33^{\prime} \mathrm{E}\right)$ and 29 specimens of Aphanius mento from Kirkgöz Springs, Antalya $\left(37^{\circ} 06^{\prime} \mathrm{N}, 30^{\circ} 35^{\prime} \mathrm{S}\right)$ by electrofishing and transported alive to the laboratory. They were kept in aquaria before killing by vertebral separation and dissection. Examination of the gastrointestinal tract was carried out using a stereoscopic microscope and all acanthocephalans were removed and counted. All specimens 
were relaxed overnight in chilled tap water, some being fixed in $5 \%$ formalin prior to storing in $70 \%$ ethanol. Some specimens were examined microscopically as wet mounts after clearing in beechwood creosote. Other specimens were fixed in 70\% ethanol, stained with iron-carmine and mounted in Canada balsam prior to examination.

Measurements were taken using an eyepiece micrometer, in micrometres unless otherwise stated, and are presented as the range followed by the mean in parentheses. Figures were made with the aid of a drawing tube. Egg refers only to fully developed, mature eggs. Fish names conform to Fishbase (Froese and Pauly 2011). Type specimens were deposited in the South Australian Museum, Adelaide, Australia (SAM) and voucher specimens in the Helminthological collection of the Institute of Parasitology, České Budějovice, Czech Republic (IPCAS).

\section{RESULTS}

Of the 66 fishes examined 35 were infected with acanthocephalans; 12 worms from 9 of 37 individuals of $\mathrm{Co}$ bitis bilseli and 236 worms from 26 of 29 individuals of Aphanius mento. Intensities of infection ranged from 1-3 worms per host for $C$. bilseli and 1-15 for A. mento.

Pomphorhynchus tereticollis was found in nine individuals of the cobitid $C$. bilseli, all from Lake Beysehir, a prevalence of $24 \%$. The morphology of the specimens, including a proboscis armature of 16-18 rows of 9 hooks, was consistent with that of $P$. tereticollis (see Špakulová et al. 2011). Cobitis bilseli, therefore, is a new host record, and Lake Beysehir, Turkey, a new locality record for P. tereticollis.

A second acanthocephalan, belonging to the Pallisentinae was collected from 26 individuals of the cyprinodontid fish, A. mento, from Kirkgöz Springs and is described below.

\section{Triaspiron gen. $\mathbf{n}$.}

Diagnosis: Gyracanthocephala Van Cleave, 1936; Quadrigyridae Van Cleave, 1920; Pallisentinae Van Cleave, 1928. Trunk small, fusiform, with regular circles of spines anteriorly and irregular spination across dorsal and ventral surfaces posteriorly, anterior and posterior spines separated by an aspinose region. Giant hypodermal nuclei present. Proboscis small, cylindrical with 3 circles of 4-6 hooks. Proboscis receptacle single-walled with cerebral ganglion near base. Lemnisci long, flat. Testes ovoid-cylindrical, tandem, contiguous or fused together. Cement gland syncytial, cement reservoir and Saefftigen's pouch present. Parasites of freshwater fishes in Turkey. Type and only known species: Triaspiron aphanii sp. n.

Etymology: The genus name refers to the spiral rows of three hooks on the proboscis (spira- $=$ a coil or twist in Latin), the name should be treated as feminine.

Remarks. The new genus is consistent with the family diagnosis of the Quadrigyridae: small to medium-sized trunk with spines encircling the anterior trunk in regular rows, proboscis globular to elongate with few hooks in spirals or circles, parasites of fishes (Golvan 1959). It falls within the Pallisentinae: anterior trunk ornamented with spines in complete circles, posterior trunk spineless or with incomplete rows of spines or with irregularly placed spines, posterior spines less robust, giant hypodermal nuclei spherical, principal lacunar canals dorsal and ventral, cerebral ganglion always at the base of the proboscis receptacle, and the lemnisci longer than the proboscis receptacle (Golvan 1959). However, the number and position of hooks on a small cylindrical proboscis and having a small fusiform trunk, with an aspinose region between regular circles of spines anteriorly and irregularly placed spines posteriorly, are not consistent with any other genus. Triaspiron gen. $\mathrm{n}$. is closest to the genera Raosentis Datta, 1947, which also has a small spindle-shaped trunk (Vankara and Vijayalakshmi 2009), and Acanthogyrus Thapar, 1927, which has a proboscis armature of three circles of six to eight hooks.

Raosentis and Triaspiron can be differentiated by the number and position of the hooks on the proboscis. Triaspiron has a total of 16 hooks arranged in an anterior circle of longer hooks and two posterior circles of smaller hooks, compared with a total of 26-30 hooks in four circles for Raosentis. The pattern of spines on the trunk, with Triaspiron having two fields, up to 40 rows of anterior spines and irregularly placed posterior spines, and Raosentis with one field, 9-17 rows of spines, on the anterior body, also distinguishes the two genera. Acanthogyrus and Triaspiron can also be differentiated by the number and arrangement of proboscis hooks and the pattern of spines on the trunk. Acanthogyrus has more than 18 to 24 hooks placed evenly in three circles, not 16 hooks arranged in one anterior and two posterior circles. Acanthogyrus has a single field of spines extending along the length of the trunk, whereas Triaspiron has two fields, one anterior and one posterior (Golvan 1959, Amin et al. 2000). The genus Raosentis is restricted to the Indian subcontinent (Vankara and Vijayalakshmi 2009). Acanthogyrus is found in Asia, Africa, Central America and Europe, the Indian subcontinent being the major centre of radiation and diversification, in cyprinid hosts. Triaspiron is found in a cyprinodontid host from Turkey.

\section{Triaspiron aphanii sp. $\mathrm{n}$.}

Fig. $1 \mathrm{~A}-\mathrm{H}$

Description (based on 9 intact and 3 damaged males; 4 intact mature, 1 immature and 2 damaged females): Qudarygyridae, Pallisentinae, with characters of genus. Small spindle-shaped worms. Trunk widest in mid region, curving ventrad. Sexual dimorphism not marked. Proboscis small, cylindrical, with three circles of spirally arranged hooks; hooks similar in both sexes. First circle of six hooks largest, blades 32-37 (34) long with simple roots almost as long as blades; second circle four hooks; third circle of six hooks all about same size, blades smaller, 12-17 (15) long, roots discoid; distance between first and second circle about twice distance between second and third circles. Apical organ shorter than proboscis. 

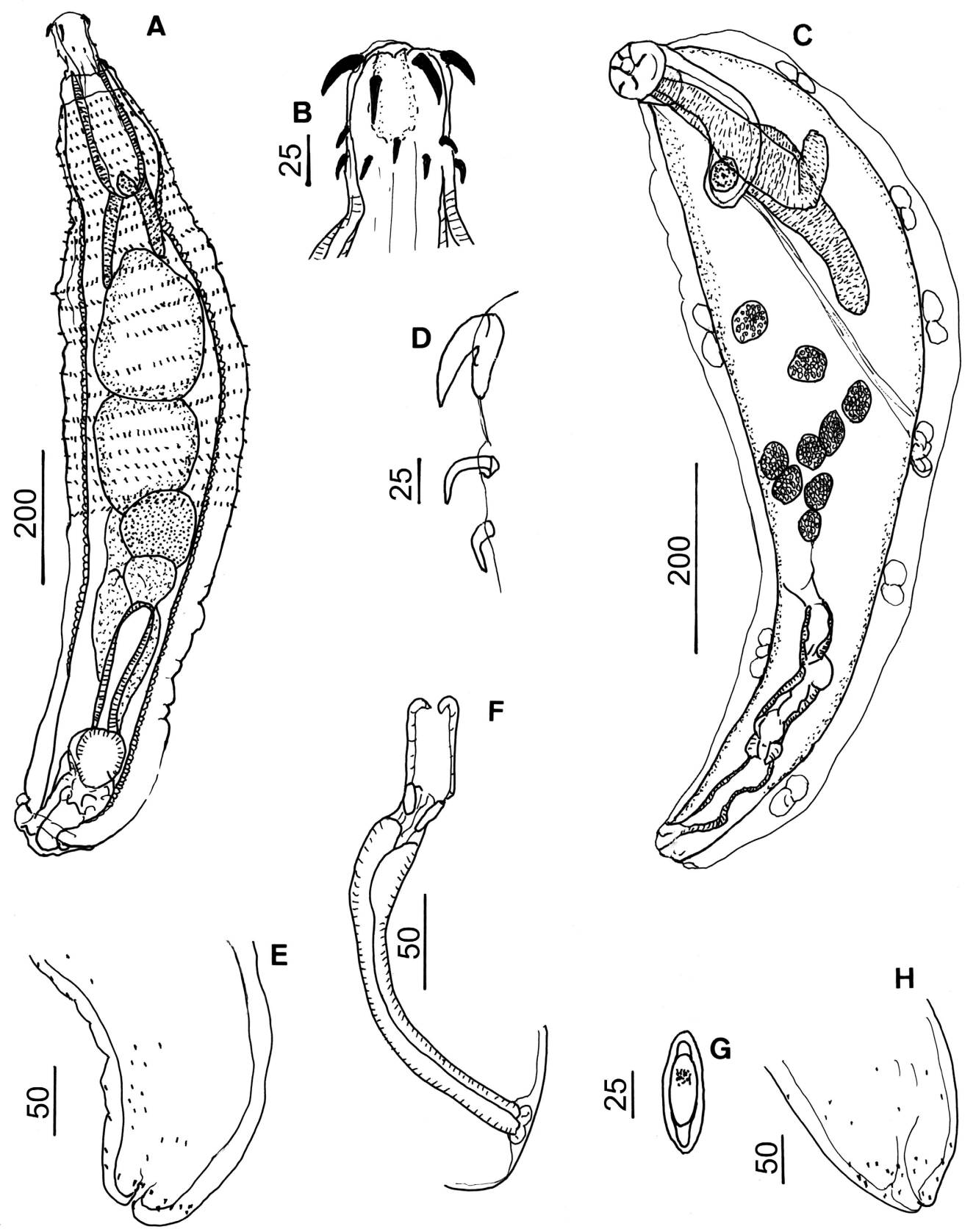

Fig. 1. Triaspiron aphanii gen. n. sp. n. A - male, lateral view showing rows of trunk spines; $\mathbf{B}$ - proboscis showing armature; $\mathbf{C}$ - immature female showing giant nuclei in tegument, trunk spines not shown for clarity; $\mathbf{D}$ - hooks, lateral view; $\mathbf{E}-$ male posterior end, lateral view, showing disposition of trunk spines; $\mathbf{F}$ - female, reproductive system; $\mathbf{G}$ - egg; $\mathbf{H}$ - female posterior end, lateral view, showing disposition of trunk spines. Scale bars are in $\mu \mathrm{m}$.

Neck relatively short. Anterior trunk with circles of small spines extending posteriorly to level of cement glands in male, about 40 circles extending about halfway down body in female; posterior trunk with irregular scattering of spines most ventral and around genital aperture. Lemnisci flat, equal, longer than proboscis receptacle. Proboscis receptacle single-walled, with cerebral ganglion at posterior end. Giant globular nuclei in body wall, six dorsal and two ventral.

Male: Trunk 938-1870 (1352) long; 201-408 (304) maximum width. Neck 34-66 (54) long, 65-85 (72) maximum width. Proboscis 60-110 (83) long, 37-69 (54) wide. Proboscis receptacle 192-304 (232) long, 53-96 (76) wide. Lemnisci 297-470 (383) long. Testes in anterior to mid body, ovoid, tandem, contiguous, may be fused; anterior testis 188-308 (263) long, 121-221 (182) wide; posterior testis 201-348 (257) long, 134-248 (202) wide. Cement gland immediately behind posterior testis; cement reservoir and Saefftigen's pouch present. Genital pore terminal.

Female: Trunk 1610-2125 (1830) long 264-595 (375) maximum width. Neck 23-66 (32) long, 66-132 
(98) maximum width. Proboscis 88-115 (96) long, 5682 (68) wide. Proboscis receptacle 255-295 (269) long, 66-93 (82) wide. Lemnisci 429-603 (514) long. Reproductive system 330 and 536 long; genital pore subterminal. Eggs spindle-shaped, with polar prolongations of fertilization membrane, 37.5-39 (38) long, 10.5-12.0 (11.5) wide.

Type host: Aphanius mento (Heckel, 1843), Cyprinodontidae. Site of infection: Intestine.

Type locality: Kirgöz Springs, Antalya, Turkey.

Type material: Holotype male SAM AHC 46329, allotype female AHC 46330, paratypes AHC 46331, voucher specimens AHC 35454, 46332, 46333, IPCAS A-82.

E ty mology: The species name is taken from the host genus name, formed as a noun in the genitive case.

\section{DISCUSSION}

Pomphorhynchus tereticollis, previously synonymised with P. laevis (Zoega in Müller, 1776), was resurrected by Špakulová et al. (2011) on the basis of both morphological and genetic evidence. Both species are found in freshwater and marine fish across Europe, may occur in sympatry, and infect the same host species (Špakulová et al. 2011). The two species can be distinguished, amongst other characters, by the number of hooks per row (8-12 compared with 11-13), the markedly more robust form of hooks 5 or 6 and the shape of the hook bases when examined in unfixed specimens (Špakulová et al. 2011). The specimens from this study were not examined as unfixed worms but the number of hooks per row, nine, is indicative of $P$. tereticollis. Pomphorhynchus laevis has previously been reported from fish species endemic to the Antalya region of Turkey (Aydogdu et al. 2011b) but it is now uncertain as to which species of Pomphorhynchus these data might refer. As suggested by Špakulová et al. (2011) a complete re-evaluation of the biogeography and ecology of the two species is now needed.

The prevalence of infection of Cobitis bilesi from Lake Beysehir with P. tereticollis, 24\%, was similar to the prevalences of $P$. laevis reported from fish hosts with distributions across Eurasia, and collected in Turkey (see for example $26 \%$ in Tinca tinca Linnaeus from Kapulukaya Dam Lake - Yildiz 2003 and 32\% in Squalius cephalus [L.] from Orenler Dam Lake - Kurupnur and Ozturk 2009) and much less than that reported from the endemic fish species Alburnus baliki Bogutskaya, Kucuk et Unlu, $79 \%$, and Capoeta antalyensis Battalgil, 60\%, collected from streams discharging into Antalya Bay (Aydogdu et al. 2011b). The intensity of infection, 1-3 worms, was lower than that reported for A. baliki and C. antalyensis (see Aydogdu et al. 2011b). However, it is now uncertain as to whether the data previously reported for $P$. laevis refer actually to $P$. laevis, or to $P$. tereticollis or mixed infections of both species.

The prevalence of infection with Triaspiron aphanii from Aphanius mento from Kirkgoz Springs, 90\%, was very high and suggests that the environment of the locality from where the fish were collected may be heavily infected. Further collections of $A$. mento throughout its range are needed to determine whether high prevalences are the norm for this host-parasite interaction or are a consequence of a particular set of conditions at Kirkgoz Springs. Further collecting is also needed to determine whether T. aphanii is either restricted to A. mento as host and to distribution in Antalya or occurs where A. mento is found.

\section{Key to the genera of the subfamily Pallisentinae}

1 Proboscis armed with 3 circles of hooks ................ 2

- Proboscis armed with more than 3 circles of hooks ...

2 Proboscis armed with circles of 4-6 hooks, unarmed region between circle 1 and circles 2 and 3; trunk with 2 fields of spines Triaspiron

- Proboscis armed with circles of 6-8 hooks, circles disposed evenly; trunk with single field of spines Acanthogyrus

3 Proboscis cylindrical, armed with 6-12 longitudinal rows of hooks; trunk with single field of spines Palliolisentis

- Proboscis short, subcylindrical, globular or subglobular, armed with 4 circles of hooks .......................... 4

4 Proboscis short, subglobular to subcylindrical, armed with 4-6 hooks in each circle; trunk with 2 fields of spines separated by an aspinose region .... Pallisentis

- Trunk with a single field of spines ......................... 5

5 Proboscis armed with hooks with circles 1 and 2 separated from circles 3 and 4 by an unarmed region .... 6

- Proboscis armed with circles of hooks aligned more or less evenly

6 Proboscis short, armed with hooks gradually decreasing in length; trunk with anterior restriction, a few circles of minute spines anterior to the restriction ......... Pararaosentis

- Proboscis subglobular, armed with circles of hooks 1 and 2 much longer and stouter than hooks of circles 3 and 4; trunk without restriction, with 9-17 circles of spines Raosentis

7 Proboscis armed with 4-5 hooks per circle; trunk with spination extending to the posterior, ventral spination in dense rows, dorsal spines more sparse . Acanthocephalorhynchoides

- Proboscis armed with 6 hooks per circle; anterior trunk with 7 circles of tiny spines Hexaspiron

Acknowledgements. We wish to thank Nesrin Emre, Mediterranean Fisheries Research, Production and Training Institute, Antalya for assistance in dissecting the fish. 


\section{REFERENCES}

Amin O.M. 1987: Key to the families and subfamilies of Acanthocephala, with the erection of a new class (Polyacanthocephala) and a new order (Polyacanthorhynchida). J. Parasitol. 73: 1216-1219.

Amin O.M., Heckmann R.A., Van Ha N., Van Luc P., NGoc Doanh P. 2000: Revision of the genus Pallisentis (Acanthocephala: Quadrigyridae) with the erection of three new subgenera, the description of Pallisentis (Brevitritospinus) vietnamensis subgen. et sp. n., a key to species of Pallisentis, and the description of a new quadrigyrid genus, Pararaosentis gen. $\mathrm{n}$. Comp. Parasitol. 67: 40-50.

Aydogdu A., Emre Y., Emre N., Altunel F.N. 2011a: The occurrence of helminth parasites (Nemathelminthes) in some freshwater fish from streams discharging into Antalya Bay in Antalya, Turkey: two new host records from Antalya. Turk. J. Zool. 35: 859-864.

Aydogdu A., Emre Y., Emre N., Kucuk F. 2011b: Two new host records for Pomphorhynchus laevis (Müller, 1776) (Acanthocephala) recorded from Antalya, Turkey: small bleak (Alburnus baliki Bogutskaya, Kücük \& Unlü, 2000) and Antalya barb (Capoeta antalyensis Battagil, 1944). Turk. J. Zool. 35: 897-900.

Erkakhan F., Atalay-Ekmekçi F.G., Nalbant T.T. 1999: A review of the genus Cobitis in Turkey (Pisces: Ostariophysi: Cobitidae). Hydrobiologia 403: 13-26
Froese R., Pauly D. (Eds.) 2011: FishBase World Wide Web electronic publication, www.fishbase.org, accessed 12/2011.

Golvan Y.J. 1959: Le Phylum des Acanthocephala. Deuxième note. La classe des Eoacanthocephala (Van Cleave 1936). Ann. Parasitol. Hum. Comp. 34: 5-52.

GÜCLÜ S.S., KÜCÜK F. 2008: Population age, sex structure, growth and diet of Aphanius mento Heckel in Russegger, 1843 (Cyprinodontidae: Teleostei), at Kirkgöz Spring, Antalya-Turkeye. Turk. J. Fish. Aquat. Sci. 8: 269-274.

Kurupnur E., Ozturk M.O. 2009: A study on the helminth fauna linked to seasonal changes and size of the fish host, Leuciscus cephalus L., from Lake Dam Orenler, Afyonkarahisar. Turk. Parazitol. Dergisi 33: 248-253. [In Turkish.]

Š́pakulová M., Perrot-Minnot M.-J. Neuhaus B. 2011: Resurrection of Pomphorhynchus tereticollis (Rudolphi, 1809) (Acanthocephala: Pomphorhynchidae) based on new molecular data. Helminthologia 48: 268-277.

VAnkara A.P., Vijayalakshmi C. 2009: Metazoan parasites of Mystus vittatus (Bloch) of River Gadavari with description of a new species of Acanthocephala, Raosentis godavarensis sp. nov. J. Parasit. Dis. 33: 77-83.

YILDIZ K. 2003: Helminth infections in tench (Tinca tinca) from Kapulukaya dam lake. Turk. Vet. Hay. Dergisi 27: 671-675. [In Turkish.] 